\title{
Os direitos de crianças e adolescentes na perspectiva orçamentária
}

\author{
Children and adolescents' rights in situations \\ of social vulnerability from budget perspective
}

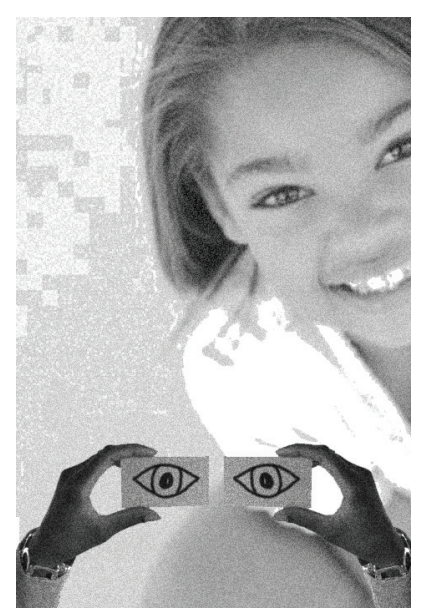

\author{
Tiago Santos Telles* \\ Vera Lucia Tieko Suguihiro** \\ Mari Nilza Ferrari de Barros ${ }^{* \star *}$
}

Resumo: As decisões governamentais devem ter como pressuposto básico o atendimento integral à infância e à juventude, em consonância com os princípios da universalização e responsabilidade pública, desenhadas na Constituição Federal de 1988. O orçamento público permite avaliar se de fato esse segmento está sendo priorizado nas políticas públicas do país. Desta forma, o objetivo deste artigo é analisar a aplicação dos recursos, realizada pelo governo federal, em programas sociais direcionados à população infantojuvenil em situação de vulnerabilidade social no Brasil.

Palavras-chave: Orçamento público. Políticas públicas. Infância. Juventude.

\begin{abstract}
Governmental decisions should be based on integral care of children and youth in line with the universality and responsibility principles, foreseen in the Brazilian Federal Constitution of 1998. The public budget is a means to asses whether in fact this segment of the population is being given priority in Brazilian public polices. The objective of this article is to analyze the application of financial resources carried out by the federal government in social programs serving children and adolescents in situations of social vulnerability in Brazil.
\end{abstract}

Keywords: Public budge. Public polices. Infancy. Youth.

* Economista, mestre pela Universidade Estadual de Londrina (UEL) - Paraná, Brasil. E-mail: tiagotelles@yahoo.com.br.

** Assistente social, doutora em Serviço Social pela PUC/SP, professora do Departamento de Serviço Social e do Programa de Pós-Graduação em Serviço Social e Políticas Públicas da UEL — Londrina/PR, Brasil.E-mail:veras@sercomtel.com.br.

*** Psicóloga, mestre pela PUC/SP, professora aposentada do Departamento de Psicologia Social e Institucional da UEL — Londrina/PR, Brasil.E-mail:mn_ferrari@sercomtel.com.br. 


\section{Introdução}

Constituição Federal de 1988, no artigo 227, e o Estatuto da Crian-
ça e do Adolescente (ECA), de 1990, em seu artigo $4^{\circ}$, reconhecem
a criança e o adolescente como prioridade absoluta e com proteção
integral. Cabe à família, à sociedade e ao Estado a responsabilidade de assegurar os direitos fundamentais, mediante formulação e execução de políticas sociais públicas, imprimindo um novo reordenamento institucional, marcando definitivamente uma mudança de concepção em relação a esse segmento da população, agora reconhecido como sujeito de direito (Souza, 1998; Nogueira Neto, 2005; Santos, 2007).

Garantir a efetivação desses direitos depende, no entanto, do planejamento e da execução dos dispêndios do governo, uma vez que a maioria de suas ações envolve custos financeiros e deve estar claramente explicitadas no orçamento público (Pires e Motta, 2006; Bornia e Lunkes, 2007). As leis que asseguram a proteção e o bem-estar de crianças e adolescentes requerem recursos, e a cobertura de seus direitos dependem de sua disponibilidade (Souza, 1998; Telles, Barros e Suguihiro, 2006). Assim, a utilização desses recursos, aliado a uma política macroeconômica responsável, permite a construção de uma rede de proteção social capaz de amparar a população mais vulnerável deste segmento (Boschetti e Teixeira, 2003). O montante orçamentário deve se concentrar em áreas prioritárias do atendimento à população infantojuvenil, evitando sua pulverização por meio de ações fragmentadas e desarticuladas.

A partir da análise dos programas e ações discriminadas no orçamento público, é possível verificar se o Estado prioriza ou não a criança e o adolescente na destinação dos proventos governamentais. Avaliar essas informações é essencial para que a sociedade civil possa fiscalizar e resguardar os direitos desse grupo (Silva e Carvalho, 2006; Mendes, 2007; Oliva e Kauchakje, 2009).

O cidadão, de um modo geral, costuma ver o orçamento público como uma matéria técnica cujo entendimento é limitado a iniciados. Essa cultura tende a gerar nas pessoas o receio de uma maior aproximação ao tema, supostamente de exclusivo interesse administrativo e que, por isto, poderia ser mantido distante do olhar da sociedade. Também é verdade que a burocracia tem feito 
pouco para diminuir essa distância, seja porque o Estado partilha desse mesmo entendimento, seja porque a difusão do conhecimento implica perda de poder (Arendt, 1998).

Naturalmente, para atender requisitos da administração pública, o orçamento apresenta termos técnicos, econômicos e jurídicos, e sua elaboração obedece a normas e jargões específicos, mas nem por isso deve permanecer restrito a especialistas. Não se pode desconhecer que, além do formalismo intrínseco à formatação dos orçamentos, encontra-se um rico processo de negociação política cuja motivação central é a definição de conteúdo e os beneficiários (Bin e Castor, 2007).

A partir da decodificação dos elementos básicos do orçamento público, este estudo tem por objetivo analisar os programas que atenderam crianças e adolescentes socialmente vulneráveis, por meio da análise da execução dos recursos autorizados, tendo por base o Plano Plurianual (PPA), a Lei de Diretrizes Orçamentárias (LDO) e a Lei Orçamentária Anual (LOA) da União, no período de 2004 a 2007, o que permite avaliar se, de fato, os princípios declarados no diploma legal brasileiro vêm sendo cumpridos, bem como a garantia dos direitos.

\section{Vulnerabilidade social de crianças e adolescentes}

Na contemporaneidade, presencia-se o desmoronamento dos princípios de proteção social, previstos pela Constituição Federal de 1988. As alterações nas formas de conceber os direitos constitucionalmente garantidos estão relacionadas às mudanças nas relações entre o Estado, a sociedade e o mercado. Um dos reflexos dessa nova agenda se reflete na reforma do Estado brasileiro ocorrido por orientações ditas "neoliberais", a partir da década de 1990. Conforme Anderson (2008), o neoliberalismo é uma ideologia teórica e política que objetiva combater o Estado intervencionista e de bem-estar, com medidas estruturais e econômicas, de forma a garantir a abertura total dos mercados, tendo por consequência a "desresponsabilização" estatal com as políticas sociais públicas.

As políticas neoliberais foram preconizadas na economia brasileira por instituições internacionais, como o Fundo Monetário Internacional (FMI), o 
Banco Interamericano de Desenvolvimento (BID) e o Banco Mundial, por meio de reformas que resultaram em uma redução do Estado em prover a proteção e a garantia dos direitos, impondo, segundo Behring e Bosquetti (2007, p. 145), "uma contraditória convivência entre universalização e seletividade, bem como o suporte legal ao setor privado, em que pese a caracterização de dever do Estado para algumas políticas, com nítida sustentação de cunho conservador".

As contradições do modelo neoliberal de compatibilizar políticas sociais com o livre mercado são evidentes, visto que as demandas de proteção social crescem demasiadamente. A pobreza, o desemprego, a exclusão, a violência e as desigualdades sociais têm colocado em tensão a relação entre as necessidades reais da população e as estratégias neoliberais adotadas para as políticas sociais. Portanto, a manutenção de um modelo reduzido de gasto social, restringe a ação estatal na determinação de diretrizes universalizantes e redistributivas para as políticas públicas. E estes aspectos refletem sobre a situação de vulnerabilidade social da população.

A concepção de vulnerabilidade amplia a compreensão sobre as situações e problemas sociais, pois reconhece que os desequilíbrios vividos por pessoas, grupos e comunidades envolvem necessidades materiais e simbólicas (Abramovay et al., 2002), e quando não atendidas em sua totalidade passam a ser de responsabilidade do Estado, da sociedade e do mercado. Esse resultado se traduz em debilidades ou desvantagens para o desempenho e a mobilidade social dos atores sociais. Enfoque que faz referência a três elementos essenciais à conformação de situações de vulnerabilidade de indivíduos, famílias ou comunidades: recursos materiais ou simbólicos, as estruturas de oportunidades e as estratégias de uso dos ativos.

Neste sentido, verifica-se que a vulnerabilidade social compreende um conjunto de fatores conectados entre si, incluindo a economia, a dimensão cultural e a conjuntura social/política, que conformam o não acesso dos sujeitos aos bens produzidos na vida social.

Ao focalizar a temática da criança e adolescente, Oliveira (1995) aponta, no cotidiano das cidades brasileiras, um conjunto de determinantes que faz com que a situação se configure como de vulnerabilidade social, que inclui todas as crianças que estão nas ruas, de variadas maneiras, ou subempregados, ou simplesmente mendigando para si ou para os pais, e os adolescentes batendo à 
porta de empregos que não existem. A vulnerabilidade social da criança pobre comporia uma lista interminável, desde a miséria estrutural, agravada pela crise econômica, que lança os provedores do lar ao desemprego, até a completa desfiguração do Estado, que não consegue resolver os problemas educacionais e da violência.

Desta forma, a vulnerabilidade social de crianças e adolescentes tem estreita relação com atual configuração do papel do Estado "mínimo", que transformou as políticas sociais em ações de caráter pontual, emergencial e compensatória. Nesta linha, Sierra e Mesquita (2006) observam que o conceito de vulnerabilidade social remete à ideia de fragilidade e de dependência de diferentes naturezas: econômica, social, afetiva, intelectual, recaindo, de modo ainda mais perverso, sobre as crianças e adolescentes - principalmente os mais pobres. Contudo, os fatores de risco que incidem sobre a vida deles não se restringem aos problemas da exclusão social, mas envolvem também os relacionamentos entre crianças e adultos, que ocorrem tanto no espaço público quanto no privado. Daí a necessidade de considerar não apenas os problemas de inserção social, mas de pensar a socialização e sua relação com os direitos da criança e do adolescente.

Assim, as formas de intervenção sobre as situações de vulnerabilidade e risco social deveriam considerar a situação das crianças e adolescentes na sua totalidade, reconhecendo aspectos advindos não apenas da condição socioeconômica, mas também dos modos de sociabilidade, das estruturas de pertencimento e produção de significados.

A escassez de recursos materiais e/ou simbólicos, aos indivíduos ou grupos excluídos da sociedade, acentua as vulnerabilidades (Abramovay et al., 2002), pois a falta de oportunidades no âmbito da educação, trabalho, saúde, lazer e cultura cerceiam o desenvolvimento pessoal, social e profissional de jovens, já que estas são fundamentais para a ascensão social. Em um contexto onde o estímulo e a valorização dos indivíduos são escassos, as chances de mudanças sociais desaparecem, sobretudo quando o Estado, a sociedade e o mercado estão travestidos de agentes competentes, harmônicos e preocupados em oferecer espaços e oportunidades para todos. Desta forma, na medida em que crianças e adolescentes não são atendidos em questões fundamentais, principalmente na área da saúde e educação, os riscos a que estão expostos, aumenta ainda mais a probabilidade de vivenciarem uma condição de vulnerabilidade social. 
Embora o ECA enfatize o segmento infantojuvenil como sujeitos de direitos garantindo-lhes proteção universal por meio de implementação e promoção de políticas sociais públicas, os investimentos em programas e projetos com ganhos sociais tem se valido das chamadas organizações sem fins lucrativos, "como agentes do bem-estar", substituindo a política pública e assumindo a condição de "alternativa eficaz" para viabilizar o atendimento das necessidades sociais. Esse apelo ao "terceiro setor" e/ou à sociedade civil se configura como um verdadeiro retrocesso histórico, caracterizada como prática assistencialista (Behring e Bosquetti, 2007, p. 162), denominada por Yasbek (2000) de refilantropização das políticas públicas. O que se pode asseverar é que nesse tipo de prática há uma transferência de responsabilidade do Estado para a sociedade, com a alegação de incentivar o voluntariado, a cooperação solidária e a pretensa "participação social". Essa tendência tem agravada a destinação do orçamento público para políticas sociais públicas, com alocação de recursos para políticas sociais privadas com recursos públicos. Esse mecanismo de manipulação de recurso orçamentário coloca o Estado na direção do interesse privado. Esta é uma estratégia de esvaziamento da política social como direito de cidadania, já que com o "desvanecimento" das fronteiras entre as esferas pública e privada, efetiva-se a privatização das responsabilidades públicas, tendo por consequência a quebra da garantia de direitos (Pereira, 2006).

Assim, as políticas sociais pensadas e gestadas em tempos de governos neoliberais têm caminhado na contramão do projeto democrático participativo. Conectadas à política pública de caráter privatista, seletiva e focalista, com institucionalização de políticas pobres para os pobres (Demo, 2006), a exemplo do programa Bolsa Família, carro chefe do governo atual. Embora, a primeira vista possa parecer um instrumento de inclusão social e redução da pobreza, para Marques e Mendes (2006), o programa Bolsa Família não se constitui um direito, e sim uma benesse governamental, que pode ser alterada sem grandes discussões, dependendo do gosto e do interesse do presidente de plantão. Em outras palavras, o combate à pobreza ainda continua a ser tratado como uma atividade meramente assistencial, o que pode resultar no florescimento de todo tipo de clientelismo. Na verdade, quando uma política social atende temporária e parcialmente a satisfação de algumas necessidades emergenciais, dissociada da capacidade de promover a elevação real do padrão de vida da população, isto significa que a política pública não cumpriu o seu papel de concretizar a cidadania e a emancipação dos sujeitos sociais. 
Por isso, para que ocorra o enfretamento da condição de vulnerabilidade social, Oliveira (1995) menciona que o Estado ainda é o trânsito para a plena assunção da cidadania por setores sociais justamente vulneráveis. Assim, a maior urgência é para que o Estado reassuma, em plena forma e vitalidade, suas funções nesse campo. Para tanto, a reestruturação financeira do Estado e de sua capacidade de investimento no campo social é condição essencial. Nada pode ser mais urgente.

O papel do Estado na destinação de recursos do orçamento público em ações que ressaltem a defesa, a promoção, a proteção e a garantia dos direitos das crianças e dos adolescentes em situação de vulnerabilidade e risco social é vital para a institucionalização de ações programáticas de caráter formativo e contínuo, na perspectiva da responsabilização do Estado enquanto provedor de políticas públicas.

\section{Processo orçamentário ${ }^{1}$}

O processo orçamentário engloba as leis previstas constitucionalmente, que pretendem garantir a realização de ações articuladas do planejamento e da organização financeira estatal. O Plano Plurianual (PPA), a Lei de Diretrizes Orçamentárias (LDO) e a Lei Orçamentária Anual (LOA) são os elementos centrais que compõem as leis reguladoras da atividade orçamentária federal. E apesar de se configurarem etapas distintas, essas leis estabelecem nexos entre si. A ideia é que, ao se integrarem, permitam um planejamento estrutural das ações governamentais.

O projeto de lei do PPA define as prioridades do governo por um período de quatro anos. De acordo com a Constituição Federal de 1988, este deve conter as diretrizes, os objetivos e as metas da administração pública federal para as despesas de capital, e outras dela decorrentes, e para as relativas aos programas de duração continuada. O PPA estabelece a ligação entre as prioridades de longo prazo, a LDO e a LOA.

A LDO estabelece as metas e prioridades para o exercício financeiro subsequente, orientando a elaboração do Orçamento, e dispõe sobre alteração na

1. Ver Telles, Barros e Suguihiro (2006), Pires e Motta (2006) e Bornia e Lunkes (2007). 
legislação tributária, bem como estabelece a política de aplicação das agências financeiras de fomento. Foi concebida para que o Executivo pudesse antecipar os critérios que deverão nortear a elaboração da LOA. Com base na LDO aprovada pelo Legislativo, a Secretaria de Orçamento Federal elabora a proposta para o ano seguinte, em conjunto com os ministérios e as unidades orçamentárias dos poderes Legislativo e Judiciário.

$\mathrm{Na}$ LOA o governo define as prioridades contidas no PPA e as metas que deverão ser atingidas naquele ano, conforme a LDO. A LOA disciplina todas as ações do governo federal, sendo que nenhuma despesa pública pode ser executada fora do Orçamento. Esta dividida em Orçamento Fiscal, da Seguridade Social e de Investimentos das Empresas Estatais.

O modelo orçamentário constitucional, prevendo o PPA, a LDO e a LOA, se encontra na ideia de orçamento-programa, já que abre amplas possibilidades para a implantação de um sistema integrado de planejamento, de sorte que o orçamento fiscal, de investimento das empresas e da seguridade social, passa a constituir etapas do desenvolvimento econômico e social, ou, se quiser, é conteúdo dos planos e programas nacionais, regionais e setoriais, na medida em que estes têm que se compatibilizar com o PPA.

\section{Crianças e adolescentes em situação de vulnerabilidade social na perspectiva orçamentária}

Por meio do Sistema Integrado de Dados Orçamentários (Sidor) e do Sistema Integrado de Administração Financeira (Siafi) foi possível verificar os programas governamentais presentes no Orçamento Geral da União e seus desdobramentos, que atenderam as demandas de crianças e adolescentes em situação de risco e vulnerabilidade social.

Para tanto, foram observadas as ações dos aproximadamente 350 programas que integraram o PPA 2004/2007 e selecionados aqueles relacionados com o objetivo do estudo. Os programas em questão, diretamente relacionados com as crianças e adolescentes em situação de vulnerabilidade social, foram: 1) Erradicação do Trabalho Infantil; 2) Proteção Social à Infância, Adolescência e Juventude; 3) Combate ao Abuso e à Exploração Sexual de Crianças e Adolescentes; 4) Atendimento Socioeducativo do Adolescente em Conflito com a 
lei; 5) Promoção e Defesa dos Direitos da Criança e do Adolescente; 6) Transferência de Renda com Condicionalidades (Tabela 1).

Em seguida, foram observados se os referidos programas estavam presentes nas LDO e LOA dos anos de 2004, 2005, 2006 e 2007. Nesse primeiro momento, constatou-se uma descontinuidade na nomenclatura dos programas constantes nesses documentos.

Foram coletadas informações referentes à execução orçamentária, sendo apresentados nesse estudo os valores autorizados e executados para cada um dos programas elegidos, bem como o percentual de execução para cada LOA, proferida no PPA 2004/2007. Foram considerados para efeito dos montantes executados os recursos liquidados, isto porque para o pagamento de qualquer despesa pública é necessário o crivo da liquidação, que consiste no direito adquirido do credor em receber seus proventos, sendo esse o estágio da execução da despesa.

O Programa de Erradicação do Trabalho Infantil (Peti), o primeiro a ser analisado, consiste em eliminar a prática do trabalho exercido por menores de dezesseis anos, salvo na condição de aprendiz a partir dos catorze anos, uma vez que a legislação brasileira proíbe qualquer tipo de trabalho para população abaixo dessa faixa etária. A ação central do programa consiste na concessão de bolsas para famílias de crianças e adolescentes envolvidos no trabalho precoce, sendo que no ano de 2004 foram atendidas 930.804 crianças e adolescentes; em 2005 este número subiu para 1.010.057; em 2006 caiu para 844.752 e, em 2007, totalizou 877.618 contemplados. Entretanto, em 2004, aproximadamente 1,45 milhão de crianças de cinco a treze anos trabalhavam (Pesquisa Nacional por Amostra de Domicílios - PNAD, 2006), em 2005 esse número chegou a 1,57 milhão (PNAD, 2006), em 2006 a 2,72 milhões (PNAD, 2007) e em 2007 a 2,50 milhões (PNAD, 2008), o que representa uma taxa de crescimento de $85,50 \%$ no período. O orçamento para esse programa seguiu uma trajetória inversa, ou seja, no ano 2004 foram executados, aproximadamente, R\$ 190 milhões (99,41\% do valor autorizado), em 2005 pouco mais de $\mathrm{R} \$ 541$ milhões (99,47\%). Entretanto, em 2006 apenas R \$ 245 milhões (68,31\%) foram executados, uma queda em relação ao ano anterior, tanto no montante de recursos autorizados quanto no percentual executado. E no ano de 2007 o valor executado foi de R $\$ 273$ milhões $(92,12 \%)$ (Tabela 1). O Peti combate a inserção precoce de crianças e adolescentes no mercado de trabalho, no qual o aspecto produtivo 
prevalece sobre o educativo. Isto ocorre porque é inerente ao sistema capitalista tirar do trabalhador o máximo da sua capacidade para o aumento da produtividade, independente de quem seja esse trabalhador, circunstância que coloca esses sujeitos etários em situação de extrema vulnerabilidade.

O Programa de Proteção Social à Infância, Adolescência e Juventude, por sua vez, funcionou apenas nos anos de 2004 e 2005, visando atender crianças, adolescentes e jovens carentes até 24 anos, em risco pessoal e social em comunidades de baixa renda. Apesar de apresentar altas taxas de execução (93,23\% em 2004 e 97,63\% em 2005), por motivos não mencionados, o programa foi extinto a partir de 2006 (Tabela 1).

O Programa de Combate ao Abuso e à Exploração Sexual de Crianças e Adolescentes busca prevenir e combater a violência, o abuso e a exploração sexual de crianças e adolescentes. A violência sexual contra crianças e adolescentes é um problema mundial. Por ser ilegal, clandestina e em grande parte doméstica, é uma questão ainda pouco visível e difícil de ser quantificada e qualificada. $\mathrm{O}$ mais frequente tipo de violência a que estão sujeitas crianças e adolescentes é aquele denominado estrutural, em função da precária situação socioeconômica das famílias das quais grande parte deles se originam. A defesa dos direitos e a proteção de crianças e adolescentes vítimas de violência e exploração sexual vêm sendo promovidas mediante ações integradas com as áreas de educação, saúde, cultura e justiça, visando a reintegração social e o retorno deles ao convívio da família e da comunidade. Estimativas indicam que, no Brasil, entre 100 e 500 mil crianças e adolescentes são vítimas de abuso e exploração sexual todos os anos (Finger, 2003). Os dados orçamentários relativos a este programa apontam que no ano fiscal de 2004, dos $\mathrm{R} \$ 37.836 .623,00$ autorizados, 95,61\% foram executados; no ano de 2005 foram executados $98,12 \%$ dos R \$ 40.216.571,00 liberados para essa finalidade. Já em 2006, o governo liberou $\mathrm{R} \$ 60.149 .839,00$ milhões, dos quais $97,62 \%$ foram executados. No ano de 2007, o montante de recursos autorizados atingiu R $\$ 75.118 .334,00$, com execução de $96,85 \%$ (Tabela 1). Entretanto, quando esses recursos são comparados com aqueles destinados a outras finalidades, como o de transferência de renda com condicionalidades (Bolsa Família), podemos entendê-los como escassos para o enfrentamento dessa problemática, pois entre as vulnerabilidades que crianças e adolescentes sofrem no país, esta talvez seja a mais grave, demandando maior atenção dos governantes. A principal ação do programa é a proteção social especial a crianças e adolescentes em situação de violência, 
abuso e exploração sexual, extensivo às suas famílias. Trata-se de um serviço que oferece um conjunto de procedimentos técnicos especializados para atendimento e proteção imediata às crianças e adolescentes e seus familiares, proporcionando-lhes condições para o fortalecimento da autoestima, superação da situação de violação de direitos e reparação da violência vivida. Por meio desse serviço, no ano de 2004 foram atendidos 17.770 pessoas; em 2005, 51.330, em 2006, 55.630, e em 2007, 55.730.

O Programa de Atendimento Socioeducativo do Adolescente em Conflito com a Lei visa ampliar e aperfeiçoar os serviços voltados para o cumprimento de medidas socioeducativas não privativas de liberdade, com intuito de humanizar o atendimento nas unidades de internação de adolescentes em conflito com a lei. No Brasil, de acordo com o Levantamento Nacional do Atendimento Socioeducativo, ${ }^{2}$ em 2002 existiam 12.051 adolescentes em atendimento socioeducativo, internação provisória e semiliberdade. Em 2004 esse número foi para 13.957 adolescentes e, em 2006, passou para 15.426. Entre 2002 e 2006 houve um crescimento de aproximadamente $28,01 \%$ no número de adolescentes cumprindo medidas socioeducativas. $\mathrm{O}$ orçamento destinado a esse programa foi R $\$ 97.108 .090$ entre os anos de 2004 e 2007, com média de execução de $81,23 \%$. No ano de 2004, foram executados R $\$ 8.665 .087,00$, $81,65 \%$ do total autorizado. No ano de 2005 houve execução de apenas 44,32\%, dos R \$ 25.447.549,00 liberados. Em 2006, foram executados 99,77\% do montante de R\$ 12.821.005,00 disponibilizado. Por fim, em 2007, foram executados R 48.837.789,00, ou seja, 99,19\% do valor autorizado. (Tabela 1).

$\mathrm{O}$ aumento no número de adolescentes que cumprem medidas socioeducativas está diretamente relacionado ao índice de reincidência, violência e contínua (sistemática) situação de cooptação desses jovens pelo crime. De acordo com Telles, Barros e Suguihiro. (2006), isto ocorre porque as ações públicas direcionadas a este público priorizam a manutenção das estruturas destinadas ao atendimento socioeducativo em detrimento de projetos e programas sociais. Assim, enquanto o Estado opta por medidas de internação (retirando, muitas das vezes, o púbere do convívio social), e não as de prevenção

2. Documento disponível em: <http://www.presidencia.gov.br/sedh/spdca/sinase>. Acesso em 1 mar. 2010 . 
e de formação, o número de jovens ligados a atividades ilícitas continua em ascendência.

O Programa de Promoção e Defesa dos Direitos da Criança e do Adolescente visa promover a ampla defesa jurídico-social de crianças e adolescentes. O programa no ano de 2004 recebeu a autorização de $\mathrm{R} \$ 43.770 .127,00$ por parte do governo federal, sendo que apenas $56,81 \%$ desses recursos foram executados. Nos anos de 2005 e 2006 a execução dos recursos foi ainda pior, $47,79 \%$ e $41,15 \%$ respectivamente. Dos $\mathrm{R} \$ 71.553 .272,00$, liberados nesses dois anos, apenas R\$ 39.481.349,00 foram executados. Em 2007 a execução foi sensivelmente superior ao período de 2004 a 2006, chegando a 93,12\% dos $\mathrm{R} \$ 24.154 .351,00$ liberados (Tabela 1).

Por fim, o Programa de Transferência de Renda com Condicionalidades busca combater a fome, a pobreza e outras formas de privação das famílias, de modo a promover a segurança alimentar e nutricional, e o acesso à rede de serviços públicos de saúde, educação e assistência social. Cria ainda a possibilidade de emancipação sustentada dos grupos familiares e de desenvolvimento local dos territórios. O programa foi o campeão no volume de recursos liberados e executados pelo governo, entre aqueles ligados à população infantojuvenil em situação de vulnerabilidade social tendo recebido no período de 2004 a 2007, aproximadamente de R $\$ 31$ bilhões, com média de execução de $96,37 \%$, e entre os programas aqui elencados, concentrou $92,31 \%$ dos recursos orçamentários. No ano de 2004, no qual foram beneficiadas 6.571 .839 famílias, a execução orçamentária atingiu $98,17 \%$ do total dos recursos autorizados (R \$ 5.799.208.123,00); em 2005 o programa atendeu 8.700.445 famílias com execução de R $\$ 6.595 .428 .049,00$ (95,17\%); em 2006 foram atendidas 10.945 .505 famílias e o valor executado chegou a R \$ 8.231.021.853,00 (92,36\%); e no ano de 2007 um total de 11.021.826 famílias foram atendidas por meio da execução de R $\$ 9.207 .821 .873,00$ (100\%) (Tabela 1).

Assim, por meio das informações obtidas torna-se evidente que o programa Bolsa Família é a principal política social do governo federal no âmbito da infância e juventude em situação de vulnerabilidade social no país. Sua ampliação é patente, tanto em relação à cobertura quanto na concentração das dotações orçamentárias executadas, e ao longo do período analisado apresentou taxa de crescimento de 35,85\%. Entretanto, trata-se de um programa de transferência de renda assistencialista, travestida de política social, que não se realiza como 
direito social. Isto porque, de acordo Marques e Mendes (2006), sua continuidade está condicionada às prioridades do projeto de um governo, sendo passível de extinção, conforme interesse e vontade política.

Desta forma, as ações direcionadas a crianças e adolescentes encontram limites na conquista e efetivação dos seus direitos, na medida em que as situações de pobreza e vulnerabilidade social continuam adiando, uma vez mais, a oportunidade destes de exercerem seu papel de sujeitos de direitos, independente de gênero, cor, raça e, sobretudo, renda familiar (Belluzzo e Victorino, 2004).

Os dados da pesquisa sinalizam que a implementação dos diferentes programas sociais tem diminuído o nível de indigência no Brasil, sem, contudo, alterar, a situação de pobreza e desigualdade social de forma substancial. É preciso investimento em políticas sociais capazes de inverter esse quadro por meio de ações programáticas que possibilitem aos sujeitos sociais o exercício da discussão coletiva, organização política e ampliação do espaço público de luta.

\section{Considerações finais}

As potencialidades de novas arenas que podem vir a estruturar campos de proteção e lutas por direitos socioeconômicos, civis e políticos constituem o estatuto legal de defesa das crianças e adolescentes. Entretanto, os esforços de abertura de canais de proteção e reivindicação são embrionários, o que sustenta a ocorrência de amplo e variado processo de destituição de direitos.

É necessário, e urgente, o debate reiterado sobre a concepção de direito no cotidiano da população, para que o termo ganhe capilaridade e reconhecimento, primeiro por aqueles que ainda não têm seus direitos garantidos e, num mesmo movimento, por aqueles que são responsáveis pela concretização de políticas sociais e com capacidade de materializar os direitos e contribuir para a realização da cidadania.

Cabe, portanto, à sociedade brasileira movimentar-se no sentido de mobilizar e lutar pela conquista de seus direitos. No cenário atual, as relações sociais estão em vastos processos de vulnerabilidade socioeconômica, civil e política, que conduzem ao que pode ser designado de processo de negação da cidadania plena. Para Behring e Bosquetti (2007, p. 195), é preciso entender que os direi- 


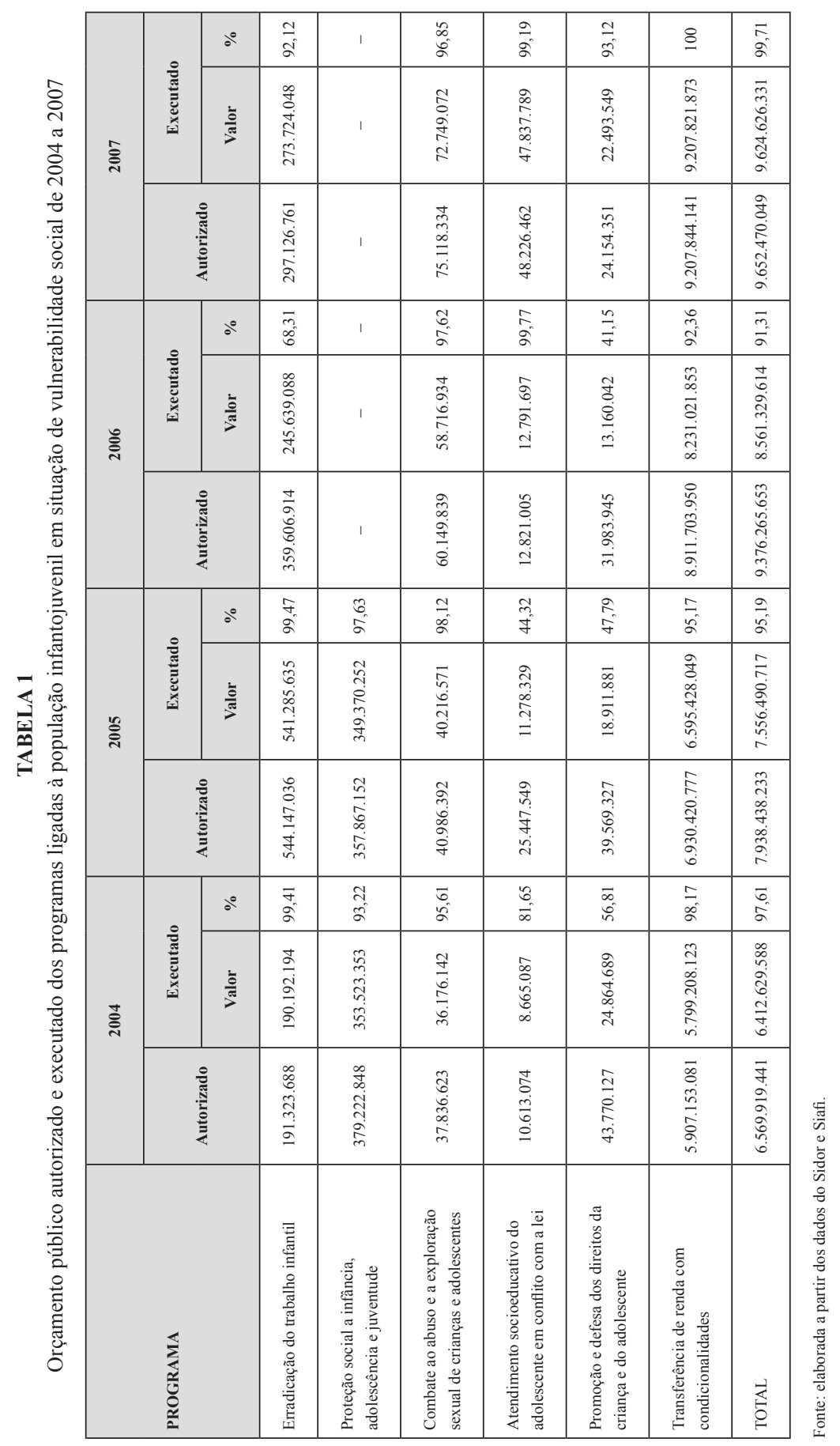

Serv. Soc. Soc., São Paulo, n. 105, p. 50-66, jan./mar. 2011 
tos no capitalismo são capazes de reduzir desigualdades, mas não são e não foram até aqui capazes de acabar com a estrutura de classes e, portanto, com o motor da produção e reprodução das desigualdades.

As políticas sociais públicas devem nortear a elaboração e a execução de programas e projetos sociais de modo a promover o desenvolvimento físico, social e emocional de crianças e adolescentes, sobretudo porque é desta maneira que eles podem conquistar reconhecimento social e valorização pessoal. A autonomia e a dignidade são elementos que devem fazer parte do cotidiano e precisam ser compartilhadas pelos grupos identitários. O combate à exclusão e à vulnerabilidade social exige ações estruturais, e estas devem estar assentadas nas condições objetivas de vida, de tal forma que as propostas possam de fato potencializar a capacidade de transformação de pessoas, grupos e comunidades. Fora desse enquadre, crianças e jovens cujas necessidades materiais e simbólicas estejam em desequilíbrio continuarão a ser sujeitos de segunda grandeza, vivendo formas de subjetivação marcadas pela "mesmice".

Assim, a estratégia para a construção de uma cidadania ativa e participativa deve estimular os espaços públicos, para que estes promovam discussões coletivas, deliberações transparentes com visibilidade ética, social e política. $\mathrm{O}$ compromisso com as expressões reais precisa ser valorizado por meio das demandas sociais, com o resgate de movimentos de ações coletivas. Cabe, portanto, investir na organização e na socialização de informações, de modo a desenvolver competências para uma gestão pública voltada para o interesse público.

Construir um sistema capaz de dar visibilidade à situação em que se encontram as crianças e adolescentes na realidade brasileira envolve o planejamento e o controle social dos orçamentos públicos dedicados a esse segmento etário, tendo por instrumentalidade legal e legitimação política a Constituição Federal de 1988. O desafio está na possibilidade de acionar a capacidade da sociedade em exercer a responsabilidade social em defesa incondicional "pelo direito de terem direitos", em uma política social neoliberal. Sem vencê-lo, jamais seremos capazes de monitorar o cumprimento da determinação legal das leis, que preconizam como prioridade absoluta a infância e a juventude.

É necessária a construção e a apropriação de um sistema de controle social amplo, sistemático e eficaz, por meio de redes de promoção articuladas pela 
sociedade civil em torno da temática dos direitos e da consolidação de um país democrático, plural e ético.

Artigo recebido em jul./2010 aprovado em dez./2010

\section{Referências bibliográficas}

ABRAMOVAY, M. et al. Juventude, violência e vulnerabilidade social na América Latina: desafios para políticas públicas. Brasília: Unesco/BID, 2002.

ANDERSON, P. Balanço do neoliberalismo. In: SADER, E.; GENTILLE, P. (Orgs.). Pós-neoliberalismo: as políticas sociais e o Estado democrático. 8. ed. São Paulo: Paz e Terra, 2008.

ARENDT, H. O que é política? Rio de Janeiro: Bertrand Brasil, 1998.

BEHRING, E. R.; BOSQUETTI, I. Política social: fundamentos e história. 2. ed. São Paulo: Cortez, 2007.

BELLUZZO, L.; VICTORINO, R. C. A juventude nos caminhos da ação pública. São Paulo em Perspectiva, São Paulo, v. 18, n. 4, p. 8-19, 2004.

BIN, D.; CASTOR, B. V. J. Racionalidade e política no processo decisório: estudo sobre orçamento em uma organização estatal. Revista de Administração Contemporânea, Curitiba, v. 11, n. 3, p. 35-56, 2007.

BORNIA, A. C.; LUNKES, R. J. Uma contribuição à melhoria do processo orçamentário. Contabilidade Vista \& Revista, Belo Horizonte, v. 18, n. 4, p. 37-59, 2007.

BOSCHETTI, I.; TEIXEIRA, S. O. Imprecisão conceitual e pulverização dos recursos federais na função assistência social. Ser Social, Brasília, v. 7, n. 12, p. 115-144, 2003. DEMO, P. Pobreza política: a pobreza mais intensa da pobreza brasileira. Campinas: Autores Associados, 2006.

FINGER, C. Brazil pledges to eliminate sexual exploitation of children. The Lancet, v. 361, n. 9364, p. 1196, 2003.

MARQUES, R. M.; MENDES, A. O social no governo Lula: a construção de um novo populismo em tempos de aplicação de uma agenda neoliberal. Revista de Economia Política, São Paulo, v. 26, n. 1, p. 58-74, 2006. 
MENDES, D. C. V. R. Representação política e participação: reflexões sobre o déficit democrático. Revista Katálysis, Florianópolis, v. 10, n. 2, p. 143-153, 2007.

NOGUEIRA NETO, W. Por um sistema de promoção e proteção dos direitos humanos de crianças e adolescentes. Serviço Social \& Sociedade, São Paulo, v. 26, n. 83, p. 5-29, 2005 .

OLIVA, J. C. G. A.; KAUCHAKJE, S. As políticas sociais públicas e os novos sujeitos de direitos: crianças e adolescentes. Revista Katálysis, Florianópolis, v. 12, n. 1, p. 22-31, 2009.

OLIVEIRA, F. A questão do Estado: vulnerabilidade social e carência de direitos. São Paulo: Abong, 1995. (Caderno Abong, n. 8).

PEREIRA, P. A. P. Mudanças estruturais, política social e papel da família: crítica ao pluralismo de bem-estar. In: SALES, M. A.; MATOS, M. C.; LEAL, M. C. (Orgs.). Política social, família e juventude: uma questão de direitos. 2. ed. São Paulo: Cortez, 2006, p. 25-42.

PIRES, J. S. D. B.; MOTTA, W. F. A evolução histórica do orçamento público e sua importância para a sociedade. Enfoque: Reflexão Contábil, Maringá, v. 25, n. 2, p. 16-25, 2006.

SANTOS, B. R. 18 anos de ECA: a inclusão de crianças e adolescentes no estado de direitos brasileiro. Inclusão Social, Brasília, v. 2, n. 2, p. 152-154, 2007.

SIERRA, V. M.; MESQUITA, W. A. Vulnerabilidades e fatores de risco na vida de crianças e adolescentes. São Paulo em Perspectiva, São Paulo, v. 20, n. 1, p. 148-155, 2006.

SILVA, G. P.; CARVALHO, C. E. Referenciais teóricos para desenvolver instrumentos de avaliação do orçamento participativo. Nova Economia, Belo Horizonte, v. 16, n. 3, p. 423-451, 2006.

SOUZA, M. R. Crianças e adolescentes: prioridade absoluta? Revista Katálysis, Florianópolis, n. 2, p. 41-48, 1998.

TELlES, T. S.; BARROS, M. N. F.; SUGUIHIRO, V. L. T. Orçamento público em provimento dos adolescentes em conflito com a lei. Revista de Políticas Públicas, Maranhão, v. 10, n. 1, p. 139-164, 2006.

YASBEK, M. C. Terceiro Setor e despolitização. Revista Inscrita, Brasília, v. 6, n. 1, p. 13-19, 2000. 